\title{
PATIENT PLANNING IN A SPINAL CORD CENTRE USING A COMPUTER
}

\author{
By R. E. CARTER, M.D., ${ }^{1}$ and C. C. JaCkson, H.S.A. ${ }^{2}$ \\ The Texas Institute for Rehabilitation and Research, Houston, Texas
}

THE problem of long-term care for the severely disabled person has been of constant concern to staff members of the Texas Institute for Rehabilitation and Research (TIRR). Realising the need for provision of dependable, care-oriented services for its patients, TIRR began a review and redefinition of care for the multiple handicapped person by utilising a shared computer system to help achieve its primary objective, i.e. continuity of patient care with provision for quality of treatment; contingent upon effective organisation.

Co-ordination of patient care activities in the Institute's Spinal Cord Centre was initiated with the use of a conversational terminal-oriented programme, a time-shared computer (IBM 360/50) located at Baylor College of Medicine (BCM), eight cathode-ray tube (CRT) display terminals with typewriter keyboards (IBM 2260), and four typewriter terminals at TIRR. This Information System, referred to as TIRRIS, was initiated in 1967, and is under control of the BCM Teleprocessing System in Houston, Texas. The Institute is a 56-bed private, non-profit hospital adapted to the care of the severely disabled patient, especially those having spinal cord injuries. This type of patient constitutes 60 to 65 per cent. of the hospital census.

\section{EVOLUTION}

In an effort to integrate the centre concept of continuity of patient care into its organisational structure, the Institute initiated its first pilot project in 1962, with assignment of a physician to each of the several disabilities treated in the hospital, i.e. the traumatic spinal cord injury, cerebral vascular accident, or chronically ill respiratory patient. During the next several years, other allied professional personnel were further assigned to the physician's team.

In 1968, the establishment of a permanent Spinal Cord Centre became official, headed by a Physician-Coordinator and assisted by a Core Planning Group. Core Planning Group members consisted of members of the Physical Therapy Department, Occupational Therapy Department, A Home Care Coordinator, a Head Nurse for the Cord Centre, Vocational Unit, as well as a Rehabilitation Nursing Specialist (RNS) and Social Worker. Although other physician specialists and professional disciplines were treating patients within the Centre, the Core Group was responsible for the planning, organisation and policy-making of the Centre itself. Each member was then responsible for relation of pertinent information to their specific departmental disciplines and for relaying any comments and critiques to the Core Group for consideration.

\footnotetext{
${ }^{1}$ Director, Patient Care Division; Physician-Coordinator, Spinal Cord Centre.

${ }^{2}$ Health Systems Assistant; Coordinator, Schedule Office.
} 


\section{PROBLEMS DEFINED}

In order for the Centre to become functional and effective, these problems had to be resolved: (a) the inordinate delay in facilitating an immediate care programme upon admission, $(b)$ the ineffective organisation of patient activities on both an inter- and intra-departmental level, and $(c)$ the difficulty in uniform understanding of the treatment programme due to the absence of a centralised source of information.

Patient information was scattered throughout the hospital, e.g. the nursing Kardex, the pink activity sheet, the physician's order form, the nursing notes, the Occupational Therapy Activity of Daily Living (ADL) card, and the Physical Therapy activity card. Many redundancies and delays, in some instances up to two weeks, resulted due to the lack of coordinated activities and the delay of communication on both the inter- and intra-departmental levels. The most obvious deterrent came at nursing shift changeover, when new orders were ineffectively communicated to or inadvertently overlooked by the nurse in charge of the oncoming shift.

\section{PROBLEMS RESOLVED}

In June 1968, as a means of facilitating an immediate care programme the Physician-Coordinator of the Spinal Cord Centre prepared a set of standing order forms for the Comprehensive Rehabilitation Programme (fig. I). These standing orders were designed to meet the immediate physiologic needs of the patient and to expedite his initial evaluation. As a result of this form, effective cooperation, and inter-departmental planning, the first computer-generated patient care schedules were produced for I4 spinal cord injured patients in October I968. These individual schedules either replaced or modified the five documents previously used and provided all team personnel with the much-needed centralised source of information at the bedside. The inclusion of the patients' care schedules as a part of the TIRR Information System afforded permanent storage of data in the computer file and ready accessibility of reference material on each individual patient. It also provided greater insight into the need for careful correlation of planning the patient activities between the departments.

Delay in producing bedside schedules to meet the immediate needs of the patient on day of admission proved a continuing problem. New programming innovations and daily generation of a 'skeleton' schedule (fig. 2) were subsequent attempts to provide the patient with a workable and immediate treatment programme. Difficulty in preparing a schedule was experienced if the turning orders were other than side-back-side due to presence of a decubitus ulcer, or the indwelling catheter had to be irrigated four times daily because of urinary tract difficulties. A delay in the realm of four to six hours post-admission was experienced when there were more than two admissions a day. Also, it quickly became evident that the skeleton schedule was requiring that all patients be dressed, bathed and given suppositories at the same time, e.g. one orderly was scheduled to dress all his patients at the same time in the morning and one aide had all her patients scheduled for baths at the same hour in the evening. The need was apparent for development of a method which would permit improvement in chronological scheduling of 
TEXAS INSTITUTE FOR REHABILITATION AND RESEARCH

SPINAL CORD INJURY - INITIAL MANAGEMENT PROGRAM

Doctor's Orders

1. Admit to TIRR. Method of Ambulation:

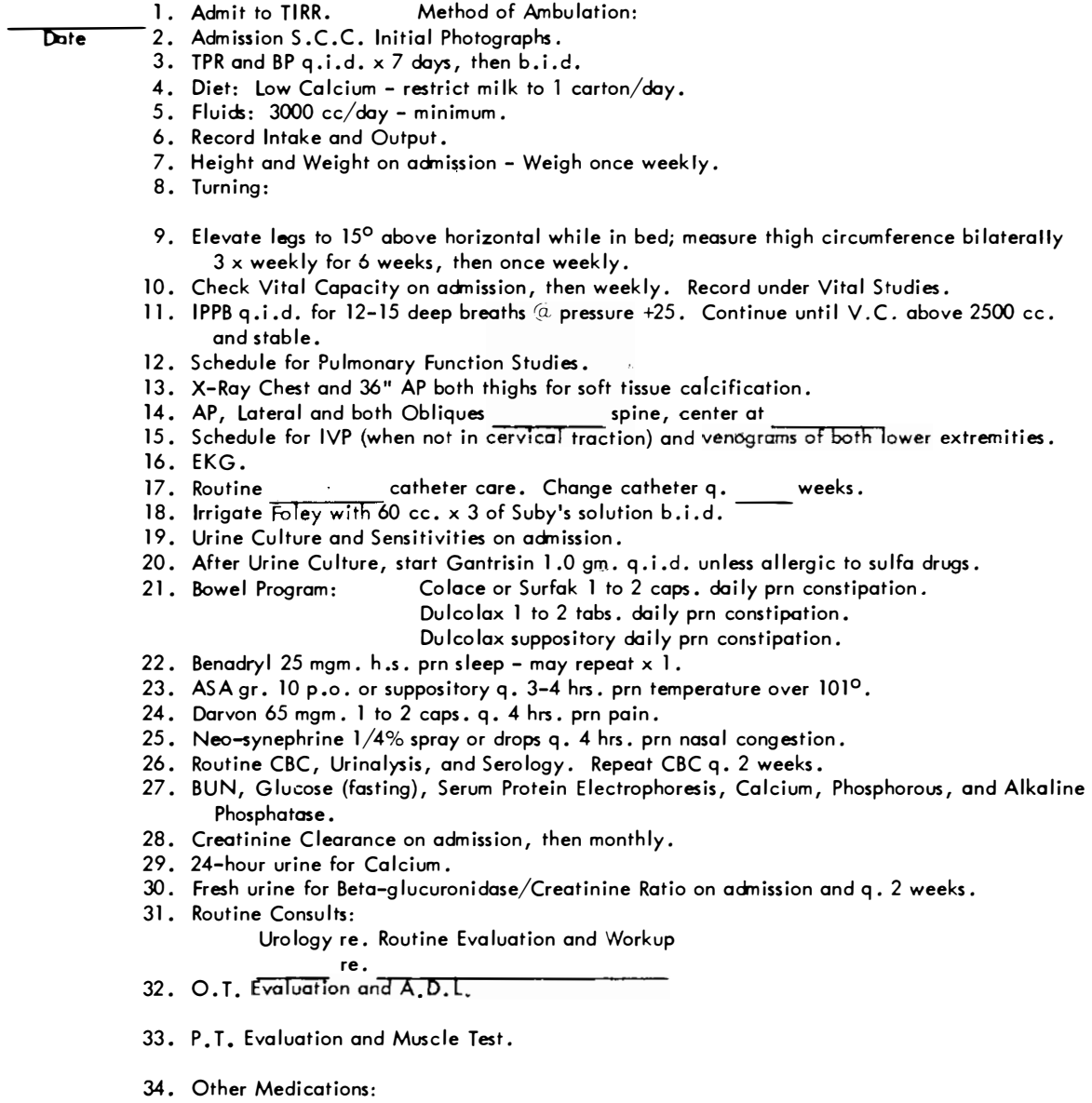

8/69-REC DOCTOR'S ORDERS

FIG. I

Standing order form for initial admission to the Spinal Cord Centre.

routine activities and expedient incorporation of turning orders, etc., into basic plans of care that would readily apply to all new admissions.

In August 1969, a method was implemented to store 'Basic Plans of Care' for the spinal cord injured patient in the computer file on a permanent basis. 
Treatment times were spaced according to nursing personnel requirements. Multiple and varying orders were entered to meet problem oriented care needs. Routine treatment was scheduled at staggered intervals in order to overcome the 'stacking' of care at one time of the day, thus reducing peak activity loads for the nursing staff and improving utilisation of available manpower.

At present there are I 4 basic plans of care for the Spinal Cord Centre available upon request from the computer file. Each plan of care is individually designed to meet the specific needs of the new admission according to the complication of

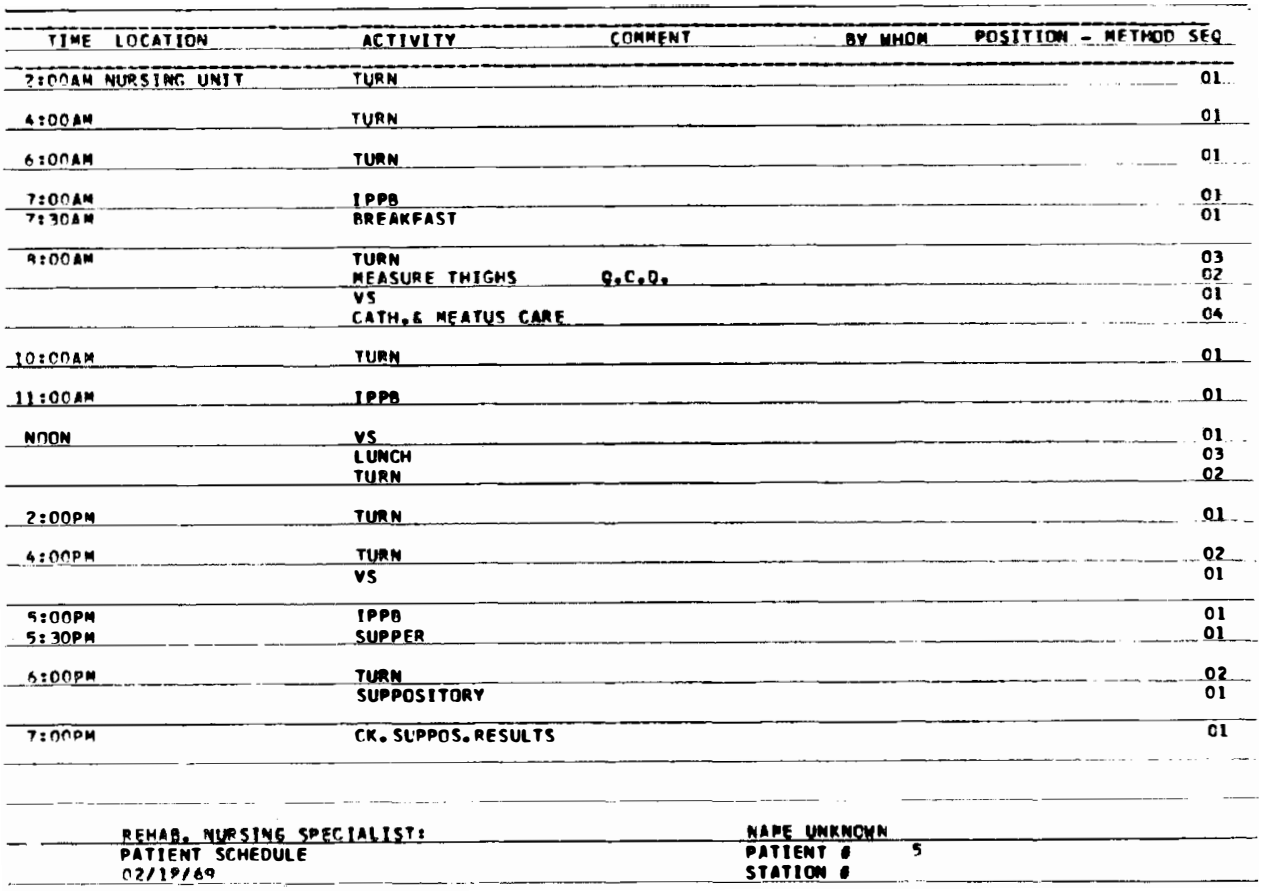

FIG. 2

First computer generated 'skeleton' schedule used for patient upon admission.

his disability. A plan of care for the new patient is obtained in less than three minutes from the computer file, and after admission the patient schedule is modified, updated, and placed at the patient's bedside within one hour of orders being written by the physician and the RNS.

Incorporation of orders and instructions from the departments into categories of patient needs, together with partially discontinuing the dual system of keeping records (manual and computer) resulted in even more practical plans of care. At the top of the care plan appears 'PRIVILEGED INFORMATION' (fig. 3) which is printed for members of the rehabilitation team. This information does not appear on the patient schedule, but is printed on the nursing station report (fig. 4) generated daily for each patient and is available for other hospital staff members on request. These data are entered as recommended by the physician, social worker, and the RNS. 
All 'INFORMATION PERTINENT TO PATIENT CARE' was listed on the upper portion of the bedside schedule. These categories are briefly summarised as follows:

Specific Events. Listing of temporary events for one day only which will interrupt the routine plan of care, e.g. Intravenous Pyelograms, Micturition Studies, and other temporary programme changes.

\begin{tabular}{|c|c|c|c|c|}
\hline 24. $\triangle D P R D A C H$ & 2E.CRNT CARE & $26 . G C A L S$ & $27 \cdot$ D.C. INFO & 06 \\
\hline \multicolumn{5}{|c|}{ INFIRMATION PERTINENT TO PATIENT CARE: } \\
\hline O1.SPEC.EVENTS & CE.STANDING & 15.SKIN THERAPY & 22.HRKG COALS & 01 \\
\hline 02. IVLEPNC LEV & OS. TRANSFER & 16. MEA SURE MENTS & 23.PERT . INFC. & os \\
\hline 03.HYGIENE & 10.C OMUNICATION & 17.6-URIAARY & NRSG UNIT - LAB & or \\
\hline Q4.RRESSINE & 11.POSITIONING & 18. BOWEL & & 05 \\
\hline O5.EATINE & 12.E OUI PMENT & 19.RESP. STATUS & & 04 \\
\hline O6.LOCOMOTION & 13.NUTRI IION & 20.RESP. RX & & 03 \\
\hline 07.SIJUING & 14.I.V. THERAPY & 21.MGMT. EO. & & 02 \\
\hline
\end{tabular}

REFAP. NURSING SPECIALIST:

PAT IFNT

$0 \geqslant 117170$

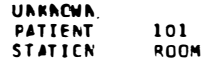

FIG. 3

Categories of patient care needs listed above the body of scheduled events on the treatment plan. 'PRIVILEGED INFORMATION' is not printed on the patient's individual bedside schedule; this is for staff use only and is generated separately.

Independence Level. Statement of level of independence in ADL, medications, catheter care and bowel programme as determined by the Physical Therapy, Occupational Therapy and Nursing Departments, e.g. WATCH: TRANSFER, EATING, MEDICATIONS.

G-urinary. Status, e.g. urinary device, type and size, along with change date due, date of last change, special tests if any, with each change, irrigations and topical medications, cautions, meatus care, and instructions in care.

Working Goals. Short-term patient goals established at weekly conferences with the patient and the Core Group. These are reviewed, modified and Independence Level changed, if progress of patient so indicates.

With each order or instruction stated, corresponding entry(ies) appear in chronological order in the body of scheduled events. 
PRIVILEGEC INFORMAI ION:

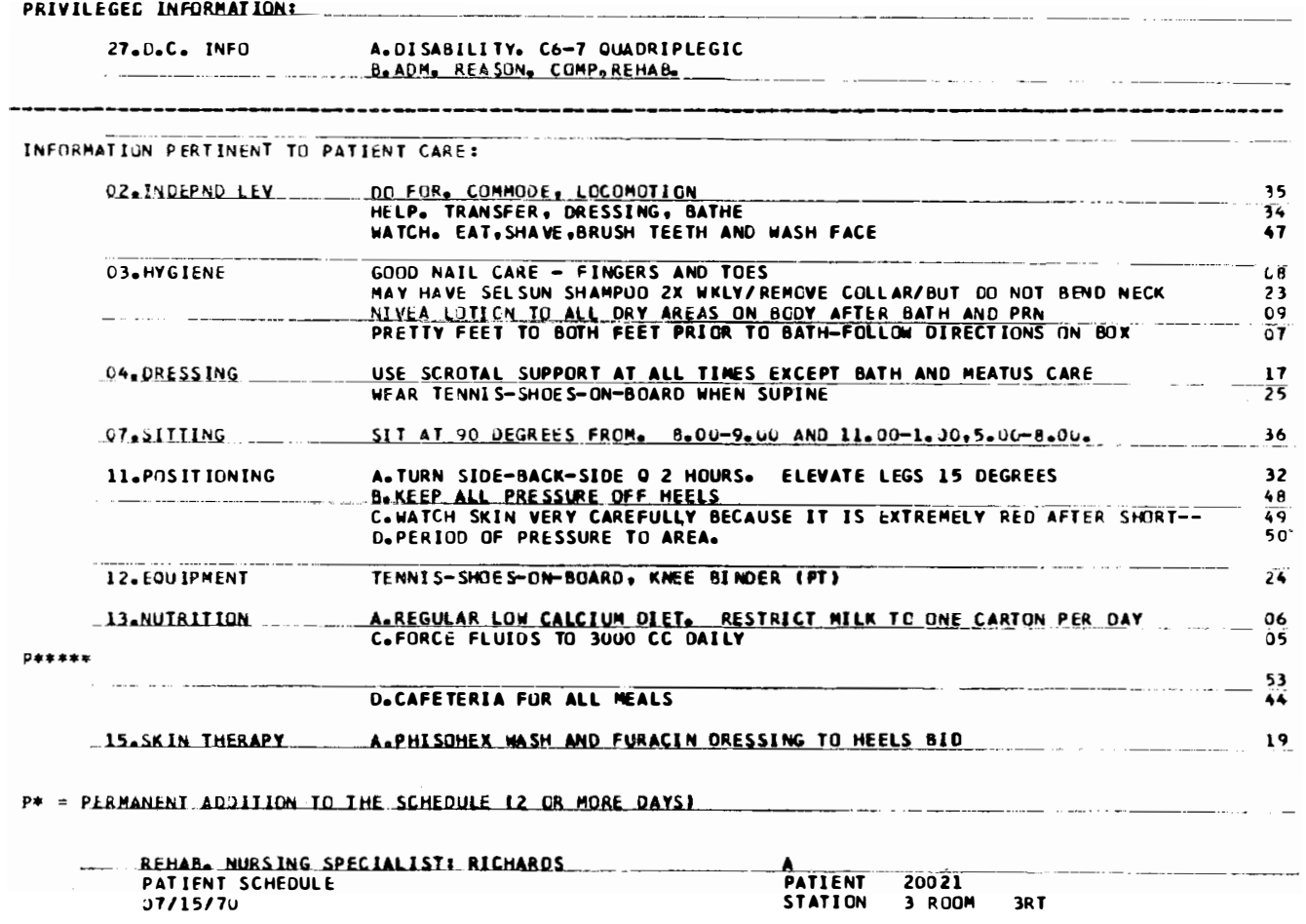

Fig. 4

Nursing report showing all orders and instructions for one patient, covering some of the categories shown in Figure 3.

\section{DAILY PROCEDURES}

A staff of three, one supervisor and two data clerks, comprise the members of the Schedule Office. Schedule data are entered by the Physical Therapy, Occupational Therapy, Clinical Laboratory and Schedule Departments on CRT Terminals (fig. 5) located in each department. Members of these departments may retrieve the patient's schedule on the terminal by listing patient number, date and time desired, to determine times available for treatment as new orders are written. They may either enter, change or discontinue treatment, whichever the order specifies, in short periods of time. The patient's schedule is continually updated with little or no communication on an interdepartmental level.

As order changes from the physician and nursing staff evolve throughout the day and evening, schedule personnel enter this data into the computer file. Data are collected as they make 'rounds' on each nursing station five times daily. Changes are incorporated into the master schedule from the bedside schedule, then edited as necessary, and entered by the data clerk into the TIRRIS file. Updated care schedules for each patient are printed on the high-speed printer at BCM before midnight and distributed by Schedule Office personnel after careful scrutiny for error. 


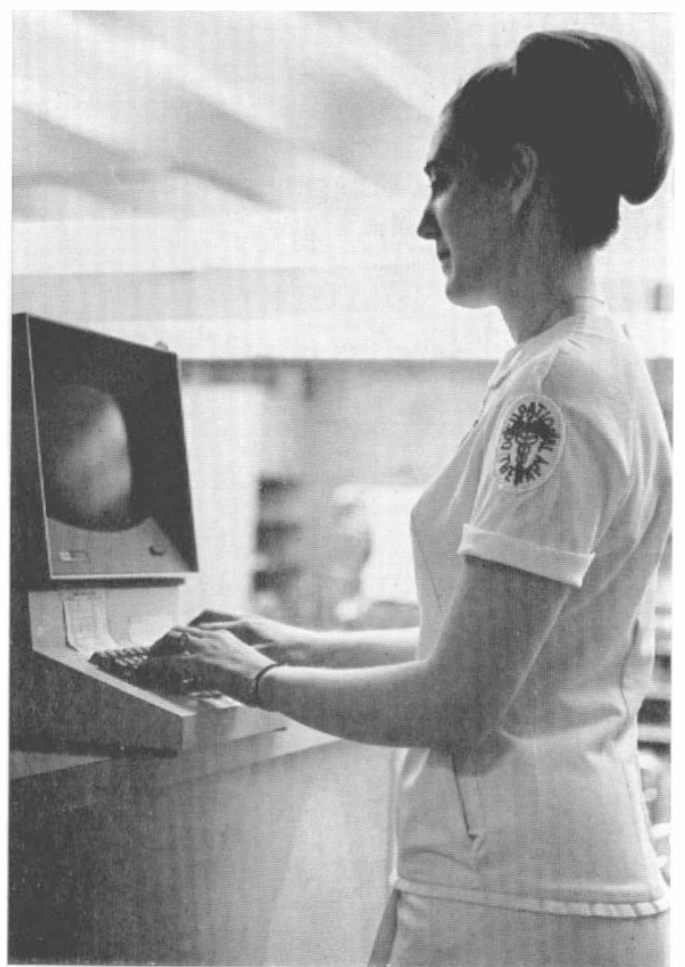

FIG. 5

Occupational Therapist entering new orders on the video display terminal located in her department.

\section{ADYANCE SCAN UF IEMPORARY SCHEOULE ENIRIES FOR $03 / 32170$}

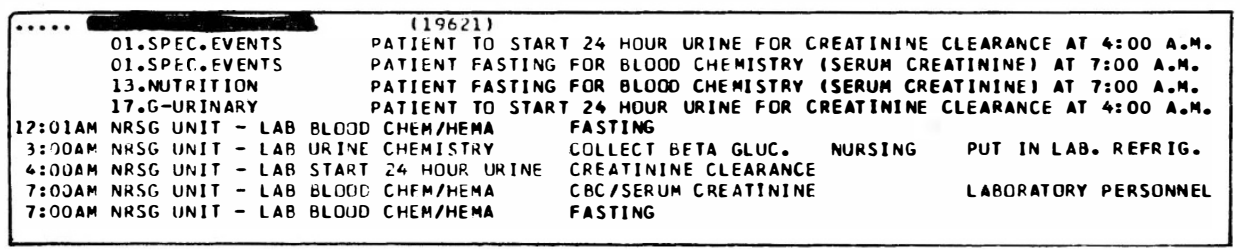

FIG. 6

Advance Scan of Temporary Entries generated for planning supply requisition needs and personnel time required three days in advance of actual performance of scheduled event. 
Cumulative chronological schedules are also distributed to all departments scheduling patient activities. Physical Therapy, Occupational Therapy, Nursing, Dietary, and the Clinical Laboratory are among those departments utilising computer output on a daily basis for assistance in planning personnel time and patient activities. A 'THREE-DAY ADVANCE SCAN OF TEMPORARY EVENTS' (fig. 6), and a 'TRANSPORTATION SCHEDULE' is also generated nightly. These print outs are 'spin-off's' of the data contained in the individual bedside schedules.

\section{SUMMARY}

In August 1969, due to the success of this methodology in the Spinal Cord Centre, the care schedules of the entire patient population of the Institute, including the Intensive Care Unit, were incorporated into the computer programme. Subsequently, basic plans of care were designed for the chronically ill cystic fibrosis patient, the spina bifida patient, and for post-operative scoliosis patients, as well as patients in tank respirators. In May 1970 there were 38 basic plans of care available for immediate use at the Institute.

In conclusion, use of the TIRR Information System has proved to be successful in that it provides: (a) problem and goal-oriented treatment plans for each patient at the bedside where the care is given, $(b)$ efficient organisation of rehabilitation team personnel time and effort, and (c) expedient and effective methods for adapting the Institute to the needs of the patient, rather than the patient to the needs of the Institute.

Acknowledgements. This project has been supported by USPHS Grants HMoo509 and HSooo88 and the SRS Grant RT-4. USPHS Grant FR00259 has provided computer support.

The authors gratefully acknowledge Misses S. Cornell and J. Testa, and Mmes. J. Fort, S. Farley, J. Carrick, and Dr. C. G. Breckenridge for their support to this project and publication.

Address of the authors: R. Edward Carter, M.D., Carol C. Jackson, H.S.A.; The Texas Institute for Rehabilitation and Research, I333 Moursund Avenue, Houston, Texas, 77025 . 